\title{
El Chance. Experiencias, tendencias y desafíos. Area Metropolitana del Valle de Aburrá (AMVA), un caso digno de replicar
}

\author{
The chance. Experiences, trends and challenges. \\ Valle de Aburrá Metropolitan Area (VAMA), a case worthy of replicating
}

Recibido: 11-06-2020 • Aprobado: 29-10-2020 • Página inicial: 137 - Página final: 168

\author{
María Alexandra Arango Mesa* \\ Ana María Gutiérrez Garzón** \\ Rose Mary Gómez Serna***
}

Resumen: con el objetivo de desestimular la ilegalidad, que crece al mismo ritmo del mercado legal o incluso más, e identificar nuevas oportunidades para las apuestas permanentes o chance en el Área Metropolitana del Valle de Aburrá, se realiza la presente investigación, conformada por un ejercicio de diagnóstico y desarrollo estratégico en el que se plantean dos ejes centrales: combatir la ilegalidad y desarrollar el mercado juvenil. Este documento no solo establece las condiciones de la industria en el territorio, también permite conocer la opinión de los principales actores de las apuestas permanentes y expertos en el sector, para comprender los motivadores más frecuentes del fenómeno y así contribuir a la transformación del mercado del chance.

Palabras clave: chance; apuestas permanentes; Juegos de Suerte y Azar; plan de mercadeo; ilegalidad; mercado juvenil.
Abstract: with the aim of discouraging illegality, which grows at the same rate as the legal market or even more, and identify new opportunities to standing or chance bets in the Area Metropolitan of the Aburrá Valley, is carried out the present investigation, made up of a diagnostic exercise and strategic development in which there are two central axes: combat illegality and develop the youth market. This document not only establishes the conditions of the industry in the territory, it also allows know the opinion of the main actors of permanent bets and experts in the sector, to understand the most frequent motivators of the phenomenon and thus contribute to the transformation of the chance market.

Keywords: Chance; permanent bets; Games of Luck and Chance; marketing plan; illegality; youth market.

* Administradora de Empresas de la Universidad de Antioquia, Especialista en Alta Gerencia de CEIPA y MBA de la Universidad EAFIT. Investigadora del Grupo Observatorio Público y docente tiempo completo adscrita a la Facultad de Ciencias Administrativas y Económicas del Tecnológico de Antioquia, Medellín - Colombia.

maralexa19@gmail.com / maria.arango92@tedea.edu.co - ORCID: https://orcid.org/0000-0002-5203-9973

** Comunicadora Social - Periodista de la Universidad de Antioquia y Especialista en Alta Gerencia de la Universidad de Medellín. Investigadora del Grupo Observatorio Público, equipo de apoyo a la implementación de la estrategia integral de control y fiscalización de los juegos de suerte y azar del Tecnológico de Antioquia, Medellín - Colombia. anagutierrezgarzon@gmail.com - ORCID: https://orcid.org/0000-0002-0589-8345

*** Profesional en Comercio Exterior de la Universidad Católica de Oriente, Especialista en Logística Empresarial de la Universidad de Medellín y Master en Dirección de Marketing de la Universidad del Mar. Investigadora del Grupo Observatorio Público, equipo de apoyo a la implementación de la estrategia integral de control y fiscalización de los juegos de suerte y azar del Tecnológico de Antioquia, Medellín - Colombia. rmgserna1@une.net.co - ORCID: https://orcid.org/0000-0001-7520-3951 


\title{
A chance. Experiências, tendências e desafios. Região Metropolitana do Vale do Aburrá (AMVA), um caso que vale a pena replicar
}

\begin{abstract}
Resumo: com o objetivo de desestimular a ilegalidade, que cresce na mesma taxa que o mercado legal ou mesmo mais, e identificar novas oportunidades para apostas em pé ou aleatórias na área Metropolitana do Vale do Aburrá, é realizada a presente investigação, composta por um exercício de diagnóstico e desenvolvimento estratégico em que existem dois eixos centrais: combate ilegalidade e desenvolver o mercado jovem. Este documento não apenas estabelece as condições da indústria no território, também permite conhecer a opinião dos principais atores da apostas permanentes e especialistas no setor, para entender os motivadores mais frequentes do fenômeno e assim contribuir para a transformação do mercado de chance.
\end{abstract}

Palavras-chave: Chance; apostas permanentes; jogos de sorte e azar; plano de marketing; ilegalidade; mercado jovem. 


\section{Introducción}

En Colombia se presenta la costumbre de apostar; en cada departamento dicho hábito varía de acuerdo con el arraigo cultural que pueda existir y cómo haya trascendido en las generaciones.

Según el Anuario de Juego en Colombia 2019 (Portafolio, 2019a), Antioquia ocupó el primer lugar en venta de chance durante el año 2018; sin embargo, el panorama sobre los ingresos por impuestos en esta modalidad de JSA, ${ }^{1}$ que recibe el sector salud, no se comparan con la cantidad de chances que se juegan a diario; este fenómeno es debido a que persiste en el mercado una serie de vendedores de chance no electrónico, que componen el chance ilegal y que no aportan recursos a la salud.

En el marco del contrato interadministrativo No. 78 de 2018, entre Tecnológico de Antioquia y la Lotería de Medellín, para

[...] el apoyo a la implementación de la estrategia integral de control y fiscalización de los juegos de suerte y azar en el departamento de Antioquia, para controlar la venta ilegal y la recuperación de recursos para Lotería de Medellín y el departamento de Antioquia (Tecnológico de Antioquia I.U., p.1).

Se realiza un estudio de mercado que dé respuesta a las necesidades de las apuestas permanentes o chance en el Área Metropolitana del Valle de Aburrá (AMVA).

En este artículo se describe el mercado del chance, específicamente las particularidades del chance ilegal, las motivaciones por las cuales este sistema sigue en crecimiento, la caracterización de apostadores y los actuales hábitos de apuestas de los jóvenes mayores de 18 años no jugadores de chance. A partir de la comprensión de esta realidad, se analizan las tendencias que marcarán el futuro del chance en el AMVA y, finalmente, se presentan los desafíos estratégicos identificados como resultados de esta investigación, que serán la base para cumplir dos metas clave, a saber, la fidelización de los clientes actuales y la conquista de nuevos nichos de mercado.

Juegos de Suerte y Azar. 


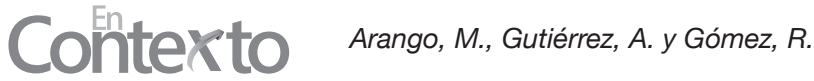

\section{Metodología}

Las posibilidades metodológicas que se plantearon para el tratamiento de este proceso de investigación pasaron por las consideraciones técnicas y experienciales del caso, pues la problemática rentística se puede focalizar, pero en todo caso hace parte de las preocupaciones cotidianas de los entes territoriales en Colombia y de las organizaciones públicas que ejercen el monopolio de los JSA.

Esta experiencia investigativa se convierte en un caso tipo de referenciar, pues pone de manifiesto las necesidades de las organizaciones por generar estrategias y políticas que viabilicen prácticas de intervención ciudadana para el control de la renta legal e ilegal, el cuidado del recurso público y la inversión social como mandato del Estado; ha sido una apuesta académico-investigativa desde el estudio de caso como foco de actuación, para aportar a la identificación de posibilidades prácticas que coadyuven al mejoramiento de las condiciones de vida de los ciudadanos, desde la protección de la salud como destinación impositiva del chance en Antioquia.

Este proceso de investigación privilegia al Departamento de Antioquia y específicamente a la Lotería de Medellín, pretendiendo que los lectores y otras entidades públicas y privadas que se encargan de monitorear o monopolizar el recurso público a través de la renta de los JSA, específicamente del chance, repliquen las posibilidades y estrategias de mejora en el comportamiento de la renta, en una línea de "buenas prácticas".

El objetivo planteado da cuenta de las aspiraciones teórico-conceptuales del estudio, pero también de las pretensiones metodológicas que le acompañan, es por ello que la descripción metodológica está alineada con el desarrollo de actividades propias que se propusieron en los escenarios de actuación del estudio, como lo fueron los municipios (10 en total) que hacen parte del Área Metropolitana del Valle de Aburrá en Antioquia, teniendo en cuenta los siguientes componentes y criterios de inclusión y exclusión.

La metodología que soporta la investigación es de tipo mixta, aplicando un método hipotético deductivo y un muestreo probabilístico aleatorio en los 10 municipios del Área Metropolitana para el análisis y triangulación de información cualitativa de la población de estudio, 678 Puntos de Venta GANA en el Área Metropolitana y 624 personas entre jugadores y no jugadores. 


\section{Caracterización del mercado de las apuestas permanentes 0 chance}

La palabra chance es un galicismo que significa: casual, fortuito, azar, oportunidad, ocasión, suerte; en Colombia es sinónimo de juego de azar y oportunidad. En los años sesenta se empezó a expandir en Colombia un JSA llamado Chance o apuesta permanente, según la versión más conocida, este juego provino de la "bolita" de Cuba, que entró por Barraquilla y luego se difundió por todo el país, de manera informal.

En Antioquia empezó a consolidarse como un negocio importante dentro del comercio local, aparecen diversos operadores, se crean empresas de apuestas permanentes, el juego se hace cada vez más popular y se extiende por otros departamentos. En los años setenta se originan fuertes conflictos legales, sociales e institucionales por la informalidad del juego y por los diferentes intereses económicos en el mercado de las apuestas. Después de arduos debates entre empresarios y parlamentarios, el juego fue legalizado con la Ley 1 del 11 de enero de 1982, la cual "autorizó a las loterías departamentales creadas con la Ley 64 de 1923 o las beneficencias que las administran para utilizar los resultados de sus sorteos en el juego de apuestas permanentes con premios en dinero" (Álvarez, 2016).

Actualmente la explotación del monopolio rentístico de los JSA está en manos del Estado colombiano, quien cobra los derechos de explotación a las entidades privadas para financiar la salud pública. El JSA preferido sigue siendo el Chance, no solo por tradición, sino porque ofrece al público varias oportunidades para ganar con una inversión mínima, cuenta con una red de comercialización amplia desde los estratos socioeconómicos más bajos. Los aportes que el Chance hizo a la salud en el 2018, por concepto de derechos de explotación, fue de $\$ 259.340$ millones; por concepto de IVA, la cifra fue de $\$ 383.845$ millones (Portafolio, 2019b).

\section{La realidad del chance en el AMVA}

Teniendo presente la necesidad de identificar las tendencias que marcarán el rumbo de los JSA, específicamente del chance, y la búsqueda de elementos o puntos de partida que permitan establecer las rutas para innovar en un mercado tan conservador, es clave partir de las realidades que se presentan en el AMVA respecto al chance como mercado y respecto a sus jugadores como integrantes estratégicos de esta ecuación. 


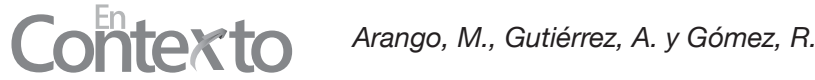

Reconocer y comprender estas experiencias, constituye el primer paso para determinar cuál podría ser el camino futuro del JSA más tradicional que existe en el país. Poner al servicio de este mercado los métodos y metodologías de investigación constituye un puente necesario entre la academia y los agentes tomadores de decisiones para convertir estos esfuerzos en iniciativas concretas de transformación (Castaño, 2019).

En las siguientes líneas, se argumentarán los tres ejes por medio de los cuales se diagnosticó el comportamiento del chance legal e ilegal en el AMVA.

\section{Tamaño físico y monetario del mercado legal e ilegal del chance en el AMVA}
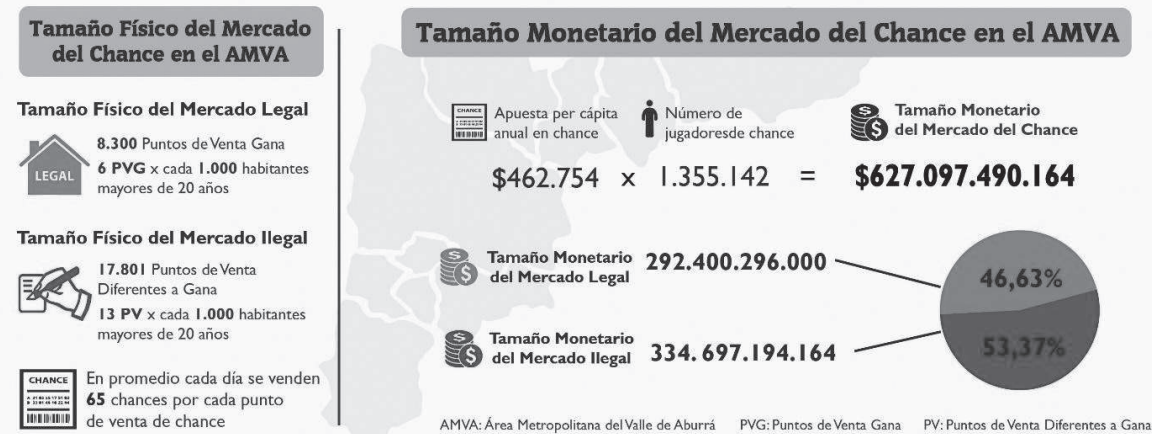

Figura 1. Tamaño físico y monetario del mercado legal e ilegal del chance en el área metropolitana del Valle de Aburrá.

Elaboración propia con datos obtenidos de encuesta propia, GANA, ${ }^{2}$ DANE, Fedesarrollo y Coljuegos.

Actualmente, Réditos Empresariales S.A. a través de la marca GANA es quien tiene la concesión para explotar el chance en Antioquia hasta el año 2021. Según sus datos, la red de puntos de venta GANA en el AMVA asciende a 8.300 en el 2019. La mayor participación está concentrada en puntos de venta tienda a tienda $(70 \%)$ y la menor, en fracción de local (1\%).

Si consideramos que, según el último censo del DANE (2019), en el AMVA el $68,6 \%$ de la población es mayor de 20 años, es decir, 2.556.872; y según Coljuegos (2017) el 53\% de la población mayor de edad apuesta en chance, podemos calcular que los jugadores actuales del AMVA ascienden a 1.355.142, aproximadamente.

2 Lotería de Medellín suministró los datos actualizados de venta de chance de los últimos cinco años. 
Ahora bien, si contrastamos los 8.300 puntos de venta en relación a los 1.355 .142 del AMVA, podemos calcular que hay una prevalencia de seis puntos de venta por cada mil jugadores del AMVA.

Según GANA, el tamaño monetario del mercado del chance para el año 2018 fue de \$292.400.296.000. El municipio con mayor participación fue Medellín con el $63,8 \%$, seguido de Bello con el 12,93\%, y en tercer y cuarto lugar: Itagüí y Envigado con 7,07\% y 5,70\% respectivamente. La apuesta per cápita anual en chance es de $\$ 215.771$.

Ya en el caso del mercado ilegal, según Zapata et al. (2018), el porcentaje de ilegalidad en el chance a nivel nacional fue de $52,7 \%$ y a nivel de Medellín y su AMVA fue del 68,2\%. Esto permite inferir que el 31,8\% del total del mercado del chance es legal. Si comparamos ambos mercados, el ilegal es 2.14 veces el legal. Así las cosas, el mercado ilegal de chance asciende a 17. 801 vendedores, expresando una prevalencia de 13 puntos de venta por cada mil jugadores del AMVA.

Con base en la apuesta per cápita anual en chance legal que asciende a $\$ 215.771$, y si tenemos en cuenta que según lo expresado previamente el mercado ilegal de chance es 2.14 veces el legal, podemos calcular que la apuesta per cápita en chance legal e ilegal ascendería a $\$ 462.754$, por tanto, la ilegal sería de $\$ 246.983$.

Con los 1.355.142 jugadores de chance en AMVA, nos daría un tamaño total monetario (legal e ilegal) de chance por el valor de $\$ 627.097 .490 .164$. Si a este valor restamos 292.400.296.000 que vale el legal equivalente al 46,63\%, nos permitiría calcular un tamaño monetario del mercado ilegal del chance por el orden de $\$ 334.697 .194 .164$ representando el 53,37\% del mercado monetario total del chance en el AMVA.

\section{Perfil del jugador de chance legal e ilegal del AMVA}

¿Hacia dónde se orienta el perfil del jugador de chace en el AMVA? Para dar respuesta a esta pregunta, se define el perfil metropolitano de los jugadores de apuestas permanentes o chance y, al mismo tiempo, se identifican algunos de los fenómenos que pueden afectar su comportamiento a futuro. 


\section{Situación actual del jugador de apuestas permanentes o chance}

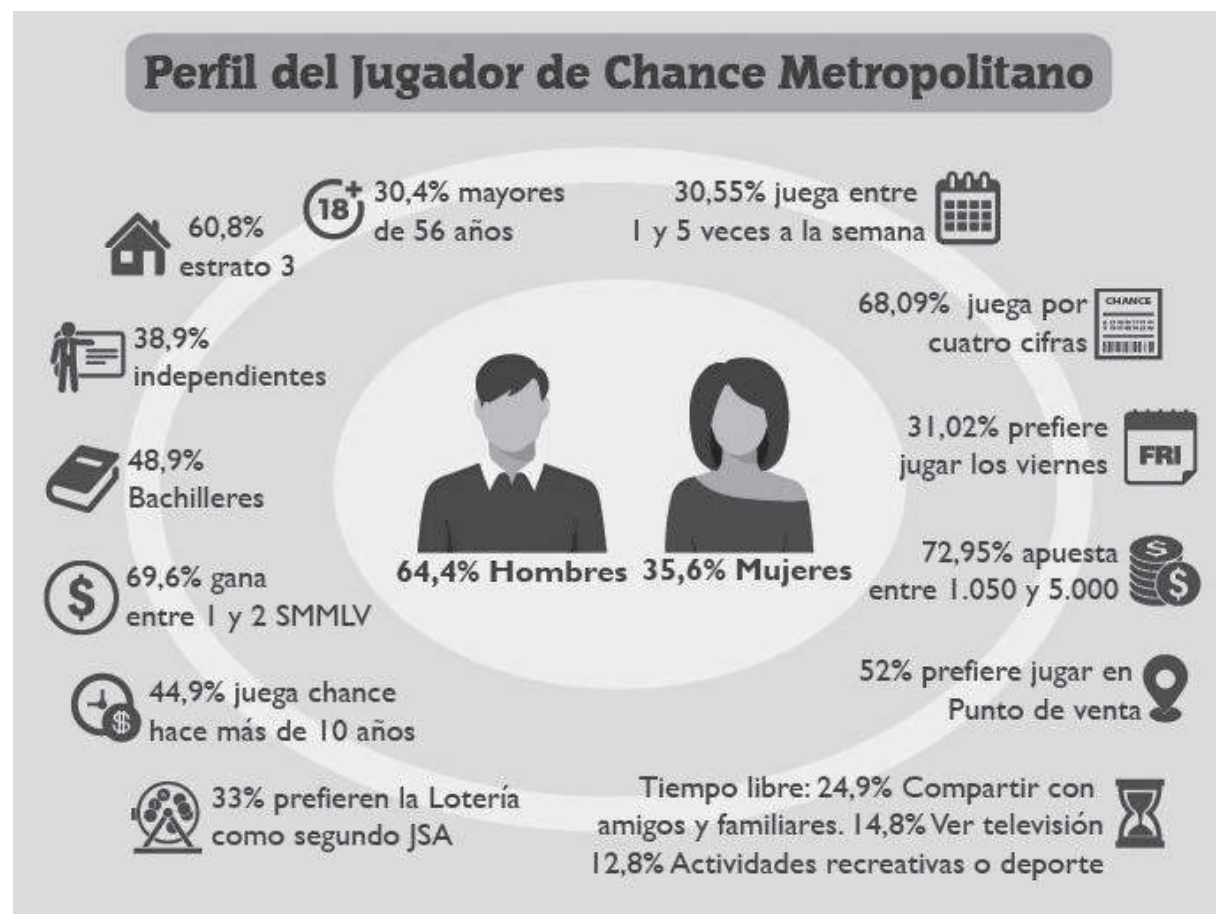

Figura 2. Perfil del jugador de chance metropolitano.

Elaboración propia, 2019.

Se encuestaron 329 jugadores de chance y 369 jóvenes no jugadores de chance de los diferentes municipios del AMVA. Las condiciones particulares del jugador de chance se presentan a continuación.

Inicialmente se establece la distribución del jugador en el territorio objeto de análisis. Medellín es una de las urbes más importantes a nivel nacional y, a su vez, al interior del AMVA es la ciudad que se destaca no solo por ser la capital antioqueña, sino porque concentra la mayor cantidad de habitantes. Para el caso de los jugadores y jóvenes no jugadores de chance se mantiene esta tendencia, el $70 \%$ y $69 \%$ de la población encuestada respectivamente, se ubica en Medellín. De acuerdo con la información recolectada, en el AMVA la mayoría de los jugadores de chance son hombres con el $64,44 \%$ de la población, y si bien las mujeres alcanzan una cifra importante del 35,56\%, al identificar en la clasificación etaria que la mayor cantidad de jugadores de chance se encuentran entre los rangos de 46 a 56 años y mayores de 56, se establece que la mayoría 
masculina se hace más fuerte, con una participación del 38,91\% sobre la femenina de tan solo el 17,93\%, en estos rangos de edad.

Respecto al nivel de formación, el 43,61\% de los encuestados tiene algún tipo de formación superior y el 27,05\% no alcanzaron a terminar el bachillerato. De acuerdo con esto, el nivel de escolarización de los jugadores de chance en el AMVA es el bachillerato, con un $48,94 \%$ de la población encuestada. Por su parte, los ingresos de los jugadores del AMVA están entre 1 y 2 SMMLV con un $69,6 \%$ del total, seguidos por quienes ganan menos de 1 SMMLV con un $23,1 \%$. La población que gana más de 3 SMMLV representa tan solo el 7,3\% de los jugadores.

Así las cosas, el grado de escolaridad en el AMVA no es una condición que garantice mejores ingresos para la mayoría de la población, y la participación en las apuestas permanentes o chance no depende de que sus jugadores tengan grandes ingresos, y quizá sí niveles básicos de formación.

En este punto resulta importante hablar de la ocupación, ya que es una condición frecuente en el AMVA y en el país, que las personas se dediquen a labores completamente diferentes a las que estudiaron y que incluso oficios no formales representen mejores ingresos.

Respecto a la ocupación, hay una mínima diferencia entre los independientes y los empleados con un $38,9 \%$ y un $36,5 \%$ respectivamente. Las amas de casa y los pensionados representan otros públicos de interés, con el 10,3\% y $9,4 \%$ respectivamente. Si bien estos últimos son una población con ingresos limitados, el 6,69\% en ambos casos tiene ingresos de hasta 2 SMMLV y gozan de una disponibilidad de tiempo muy diferente respecto a los independientes y empleados con los mismos ingresos.

Para los colombianos, los JSA son actividades que les ayuda a bajar la tensión del día a día, y particularmente el chance, se ha convertido en un mecanismo para tener acceso a dinero extra que por sus pequeños montos se usa principalmente para ajustar los ingresos del mes (Coljuegos, 2017). De acuerdo con esto, tiene sentido que, por los costos de vida en el país, ingresos de entre 1 y 2 SMMLV, que son los que tienen la mayoría de los jugadores de chance del AMVA, no les sean suficientes para solventar sus necesidades y su estilo de vida, y por tanto deban recurrir al azar para mejorar sus condiciones. 


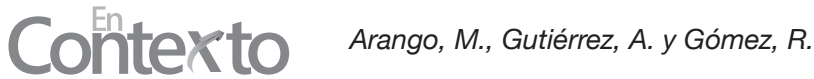

Aunque la vida de una persona soltera y una casada o en unión libre puedan resultar muy diferentes, no parece existir una diferenciación radical entre estas condiciones, y no se identifican como limitantes a la hora de apostar en chance. El uso del tiempo libre como factor importante a la hora de determinar algunas estrategias de mercado evidencia que el jugador metropolitano invierte su tiempo de ocio en tres actividades principalmente: compartir con amigos y familiares con el $24,9 \%$, un reflejo de la cultura paisa sumamente familiar y social; ver televisión con el 14,8\%; y actividades recreativas o deporte con un $12,8 \%$. Se resalta que otras actividades relacionadas con la práctica de la apuesta son vistas como recreativas para el 13,57\% de la población encuestada.

Respecto a los ingresos del jugador, el uso del tiempo libre no tiene ninguna variación, dado que las actividades seleccionadas no requieren inversiones representativas para llevarse a cabo. En referencia a la edad del jugador, el cambio es mínimo respecto a las actividades favoritas, ya que pesa más el componente cultural y social de los antioqueños sobre su clasificación etaria. Sin embargo, se resalta que los jugadores de chance jóvenes tienen un comportamiento un poco diferente. Compartir con amigos y familiares sigue en primer lugar con un 5,14\%, pero le siguen actividades recreativas o deportes con el 3,61\% y Netflix con el $2,74 \%$ que no tiene una participación representativa desde un enfoque general.

Teniendo claro que el instrumento de encuesta se les aplicó a los jugadores de chance, es apenas natural que el juego de azar favorito sea las apuestas permanentes, con el $86 \%$ de los encuestados.

Esta pregunta, en la que se establecían las preferencias de juego y en la que se podían elegir varias opciones y establecer el orden de favoritismo, también arrojó que la lotería ocupa el segundo lugar con el 34\% y el Superastro el tercero, con un $27 \%$. Incluso al analizar esta variable bajo el paquete de motivadores establecidos para esta investigación, se mantiene la misma tendencia de comportamiento respecto al favorito y se identifican el dinero extra y la tradición familiar como los principales motivadores que impulsaron a los jugadores a iniciarse en el chance, e incluso como factores que siguen siendo influyentes en sus conductas de juego.

No solo se trata de que la mayoría de los antioqueños crecieron viendo jugar chance a sus mayores, también es un JSA vinculado a la memoria y corazón de los colombianos, siendo la primera mención cuando se habla de este tópico y el juego más comprado en la categoría de JSA (Coljuegos, 2017). 


\section{Situación actual del jugador de chance ilegal}

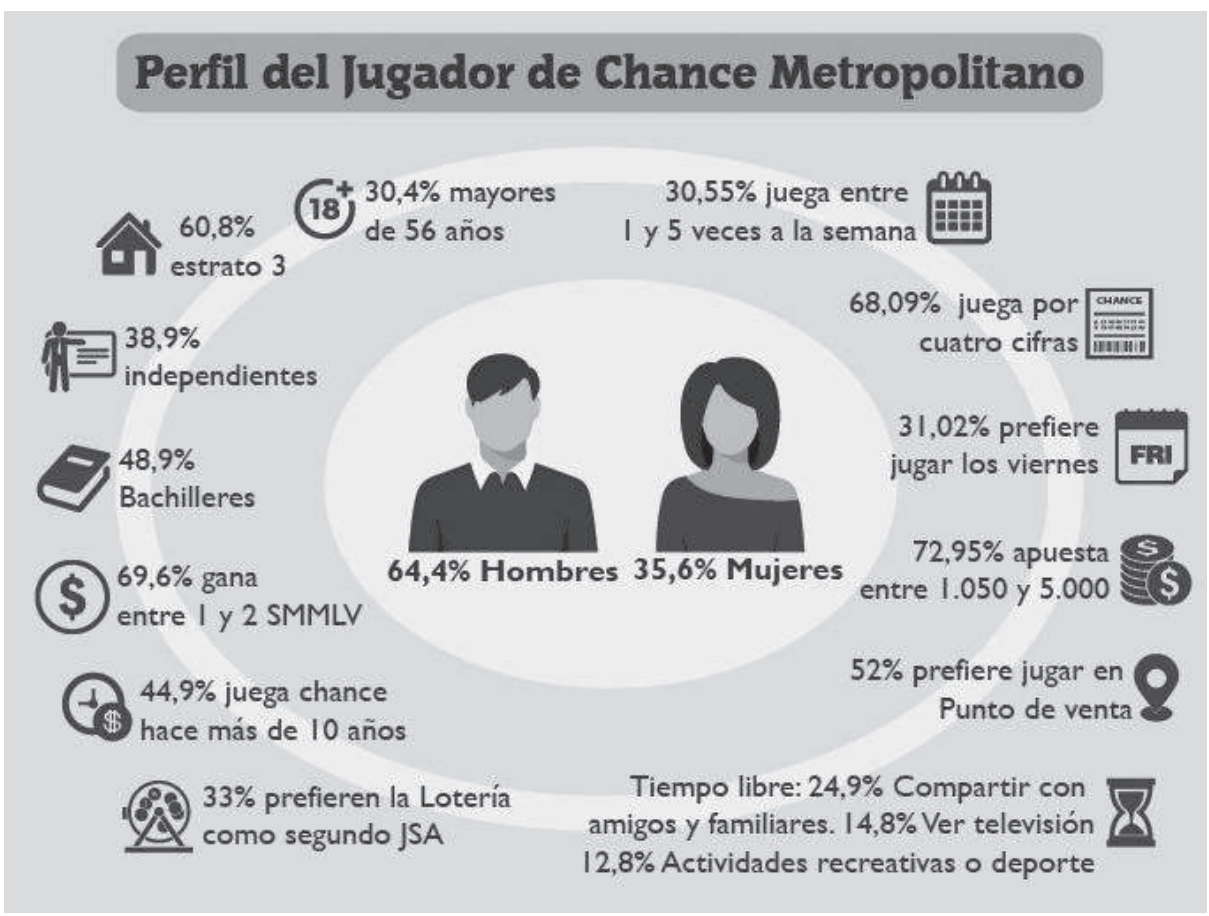

Figura 3. Perfil del jugador de chance ilegal metropolitano.

Elaboración propia, 2019.

Como ya se había mencionado, se encuestaron 329 jugadores de chance de los diferentes municipios del AMVA. No obstante, existen algunas diferencias entre el jugador que apuesta en puntos de venta GANA y los que lo hacen de manera ilegal.

Una de las principales barreras para acceder a la información del mercado ilegal es que por sus características no todas las personas están dispuestas a revelar su preferencia por este tipo de apuestas. En línea con esto, tan solo el $7,8 \%$ de los encuestados informaron utilizar medios diferentes a los oficiales para hacer sus apuestas. Sin embargo, a través de las preguntas de control, se pudo establecer que la cifra de jugadores ilegales en promedio sería muy superior, alcanzando el 52,5\% de los encuestados, número que coincide no solo con el estudio realizado por Fedesarrollo, sino también con las estimaciones realizadas para la presente investigación. 


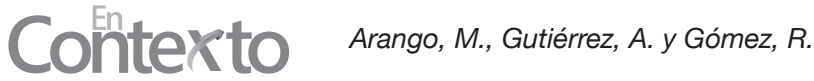

Para analizar la situación del jugador de chance ilegal es importante entender que, respecto al jugador de chance electrónico, las características no son significativamente diferentes; encontrando incluso que muchos de ellos juegan en ambos mercados con el fin de diversificar sus apuestas e incrementar las posibilidades de ganar más dinero por cada chance.

Dentro de las generalidades demográficas, se puede decir que la mayoría de los apostadores de chance no electrónico, se encuentran ubicados en Medellín, seguido por Bello, en donde se presenta una mayor proporción de apuestas hechas por mujeres, y por Itagüí, en el que los mayores apostadores son de género masculino, este último factor preponderante en los demás municipios del Valle de Aburrá.

Al analizar el género respecto a la edad del jugador de chance ilegal, se encuentra que en la población masculina predominan las personas adultas, especialmente los mayores de 56 años; mientras que, en las mujeres, la principal concentración se encuentra en el rango de 36 a 46 años, con el 13,04\%.

Para hombres y mujeres, la principal actividad económica es la vinculación laboral, con el 40,91\% y el 33,78\% respectivamente. La segunda ocupación más frecuente, para ellas, es la de ama de casa con el 29,73\%; para ellos, las actividades independientes con el $38,18 \%$.

Otro aspecto a señalar es que las personas que juegan chance no electrónico en su mayoría poseen niveles básicos de formación e ingresos limitados, incluso por debajo de la media establecida para los jugadores de chance legal, esta condición hace que el chance sea visto como una oportunidad de mejorar los ingresos con una relativa baja inversión.

Es importante rescatar que la segunda opción para los jugadores de chance no electrónico es la lotería, seguido de Superastro y apuestas deportivas, en ese orden, muy en sintonía con la tendencia nacional (Coljuegos, 2017).

\section{Perfil del joven no jugador de chance}

La población joven hace parte de un grupo etario exigente, son consumidores expertos o con la capacidad para pasar fácilmente de no saber nada de un producto a conocer todas y cada una de sus características. Son altamente influenciables y este suele ser un factor para modificar sus decisiones de compra. 
Entre los jóvenes no jugadores de chance tenemos quienes sí sienten afinidad por los JSA, pero que no se interesan particularmente por el chance, y los jóvenes no jugadores de ningún tipo de JSA. Conocer este perfil, en el área metropolitana, es el objetivo del siguiente apartado.

\section{Situación actual del joven no jugador de apuestas permanentes o chance}

\section{Perfil del Joven No Jugador de Chance Metropolitano}

$56,9 \%$

(18) $60,96 \%$ entre 18 y 25 años

\section{$62,57 \%$ lleva apostando
en JSA hasta 5 años} estrato 3

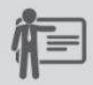

$33,9 \%$

Estudiantes

$48,2 \%$

Bachilleres

(\$)

$62,2 \%$ gana

entre I y 2 SMMLV

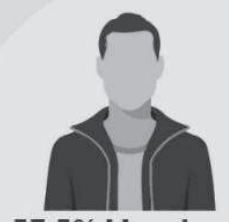

$\mathbf{5 7 , 5 \%}$ Hombres

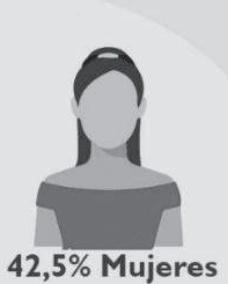

$62,02 \%$ prefiere jugar en canales digitales

$53 \%$ prefieren las apuestas deportivas

$70,85 \%$ apuesta en promedio $\$$ menos de $\$ 10.000$

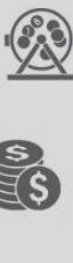

Tiempo libre: $22,8 \%$ Compartir con amigos y familiares. 15\% Actividades recreativas o deporte. 12,4\% Dormir. II, I\% Netflix

Figura 4. El joven no jugador de chance metropolitano.

Elaboración propia, 2019.

Se encuestaron 369 jóvenes no jugadores de chance de los diferentes municipios del AMVA. Para efectos de esta investigación, se considera como público joven a los habitantes que se encuentran entre los 18 y 35 años de edad. La muestra de esta población está conformada en su mayoría por la porción más joven, es decir, entre los 18 y 25 años, quienes representan el 60,98\%. También es importante mencionar que los jóvenes que participaron de esta encuesta tienen como común denominador no jugar chance; sin embargo, pueden ser activos apostadores de otros JSA o no participar de ninguno de ellos. 


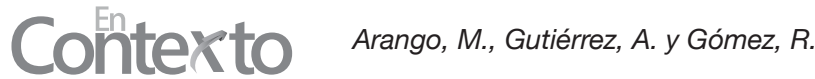

Medellín como capital antioqueña concentra la mayor cantidad de habitantes $\mathrm{y}$, por consiguiente, la mayor presencia de jóvenes no jugadores de chance con un $69 \%$ de la población encuestada. Se resalta que los demás municipios, Bello e Itagüí, van justo después de Medellín con una participación del 14\% y $9 \%$ respectivamente.

De acuerdo con el trabajo de campo realizado, en el AMVA la mayoría de los jóvenes no jugadores de chance son hombres, con el 57,45\% de la población. Las mujeres alcanzan una cifra representativa, con el 42,55\%. Empero, aunque la cantidad de jóvenes no jugadores de chance se concentran entre los 18 y 25 años y la brecha es casi inexistente entre hombres y mujeres, una vez se alcanza el siguiente rango etario, entre 26 y 35 años, la población de hombres se duplica y las mujeres jóvenes pierden protagonismo, con una participación de tan solo el $13,82 \%$.

Se infiere también que los jóvenes son en su mayoría estudiantes, trabajadores independientes o empleados, y aunque no se estableció esta pregunta en el cuestionario, es muy probable que un porcentaje representativo de estos jóvenes sea simultáneamente estudiante y empleado o independiente. No obstante, su ocupación no determina su estrato socioeconómico, pues en todos los casos predomina el estrato 3, con una participación conjunta del $56,91 \%$.

Respecto al nivel de formación el 24,02\% de los encuestados, estos tienen algún tipo de formación superior y menos del $10 \%$ no han terminado el bachillerato. De acuerdo con esto, el nivel de escolarización de los jóvenes no jugadores de chance del AMVA es bachillerato, con un 48,24\% de la población encuestada, lo que tiene estrecha relación con el rango de edad en el que se encuentra la mayoría. Por su parte, los ingresos de los jóvenes no jugadores de chance del AMVA están también entre 1 y 2 SMMLV con un $62,2 \%$ del total, seguidos por quienes ganan menos de $1 \mathrm{SMMLV}$ con un $31,8 \%$, lo que no es de extrañar pues la principal ocupación de esta población es académica, con un $33,9 \%$ de la muestra. La población que gana más de 3 SMMLV representa tan solo el 6\% de los jóvenes no jugadores de chance.

En relación con estos tópicos, se encuentra la ocupación, que no necesariamente está asociada con lo estudiado y sí con la fuente de ingresos. Como ya se había mencionado, el 33,9\% de los encuestados son estudiantes, pero le siguen de cerca los empleados con el 31,4\% y los independientes con el 25,5\%. En relación con los ingresos predominantes de entre 1 y 2 SMMLV, la mayor participación la tiene los empleados con un $24,73 \%$ y los independientes con 
un $19,29 \%$. Los estudiantes en este rango de ingresos representan el 13,32\% y se evidencia que tienen alguna actividad económica que les representa dinero de manera estructurada, una condición común en el país: estudiar y trabajar.

El estado civil arroja otras perspectivas sobre este tipo de público, si bien los casados y en unión libre representan el $24,19 \%$, la característica predominante entre esta población es la soltería con un $75,27 \%$, condición que tiene un efecto en la destinación de los ingresos que perciben, ya que aunque ganan lo mismo que los jugadores de chance metropolitanos e incluso que la mayoría de los colombianos, no poseen las obligaciones financieras que los casados y, por consiguiente, pueden destinar una porción más grande de sus ingresos a actividades de ocio y recreativas como apostar.

De allí, la importancia de analizar el uso del tiempo libre como factor clave a la hora de determinar algunas estrategias de mercado y así abordar al joven en sus escenarios de disfrute ideales.

Compartir con amigos y familiares se mantiene como la actividad favorita con el 22,8\%, un comportamiento tradicional que ha superado la barrera de la edad. Le siguen las actividades recreativas o deporte con un 15\%, dormir con un $12,4 \%$ y Netflix con el $11,1 \%$. Esta misma variable, analizada a la luz de los ingresos, mantiene el mismo orden de predilección, pero también aparecen otras actividades muy cercanas en porcentaje como ver televisión y actividades en redes sociales, muy propias de la comunidad joven y que permiten dilucidar canales de comunicación efectivos para entablar relación con estos prospectos. Los favoritos de los jóvenes son las apuestas deportivas, los videojuegos y el casino, en ese orden de prioridad; juegos muy llamativos por la afinidad presente con estos temas y por la adrenalina que supone participar en este tipo apuestas, ambas sensaciones altamente valoradas por el público joven.

Sobre los inhibidores más representativos del público joven, se les consultó a los demás públicos encuestados para esta investigación. Al respecto, el peso más representativo, para los jugadores de chance y los puntos de venta GANA, lo tiene la poca probabilidad de ganar con un $42 \%$ y un $31 \%$ respectivamente, y aunque esta variable también fue importante para los puntos de venta diferentes a GANA, con un 37\%, esta población consideró que el factor de mayor impacto es que el chance no se encuentra asociado a pasiones como el fútbol, con el $42 \%$. Los jóvenes también respondieron a esta pregunta y la poca probabilidad de ganar también fue la respuesta más recurrente con el 38\%. 


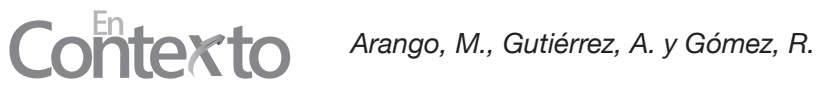

En el ranking de los principales motivadores para que los jóvenes no jugadores comiencen a apostar en chance, se encontró que los encuestados resaltaron los ingresos adicionales como el mayor incentivo, con el $40 \%$; seguido de la tradición, con un 36\%; y las cuantías bajas y mayor probabilidad de ganar, con un $12 \%$. Sobre las otras características del chance, que podría influir en el comportamiento de las apuestas de los jóvenes, se subrayan un mejor plan de premios, en el que se incluyan bonos o beneficios pensados exclusivamente para ellos, y el fortalecimiento del canal digital para realizar las apuestas en línea.

\section{Retos para combatir la ilegalidad y desarrollar el mercado juvenil en el chance}

Entendiendo el comportamiento actual del mercado y de los actores que intervienen en él, tanto en el ámbito legal como ilegal en el AMVA, volcamos el interés de esta investigación hacia las líneas de desarrollo y crecimiento que están generando impactos importantes en un marco general, para identificar cómo este movimiento incidirá en el desenvolvimiento de los JSA y, por ende, cuál sería la pauta a seguir de cara al futuro.

Se identifican 19 tendencias de gran relevancia para el mercado del chance y que de una u otra forma, intervendrán o afectarán la evolución de sus jugadores, del mercado, y de quienes son objeto de interés para el mismo. 
El Chance. Experiencias, tendencias y desafíos...

Tabla 1

Tendencias para direccionar el chance en el AMVA

\begin{tabular}{|c|c|}
\hline Tendencias & Descripción \\
\hline $\begin{array}{l}\text { Crecimiento demográfico y } \\
\text { de hogares. }\end{array}$ & $\begin{array}{l}\text { La tendencia demográfica del AMVA ha sido creciente } \\
\text { en los últimos } 13 \text { años, con una tasa de crecimiento } \\
\text { intercensal del } 12 \% \text {. }\end{array}$ \\
\hline $\begin{array}{l}\text { Reducción de la migración } \\
\text { interna departamental. }\end{array}$ & $\begin{array}{l}\text { La migración interna a nivel departamental muestra } \\
\text { que en } 5 \text { años hubo una reducción de las personas que } \\
\text { inmigran y emigran entre los municipios, expresada en } \\
-73 \% \text { y }-65 \% \text { respectivamente. }\end{array}$ \\
\hline Urbanización. & $\begin{array}{l}\text { Actualmente el AMVA vive un fenómeno de alta } \\
\text { densidad poblacional en áreas urbanas, con especial } \\
\text { énfasis en el norte. }\end{array}$ \\
\hline $\begin{array}{l}\text { Crecimiento del índice de } \\
\text { envejecimiento. }\end{array}$ & $\begin{array}{l}\text { La relación entre la población adulta ( } 65 \text { años y } \\
\text { más) con la población de niños o jóvenes (menores } \\
\text { de } 15 \text { años) del AMVA tuvo una tasa de crecimiento } \\
\text { intercensal del } 123 \% \text {. }\end{array}$ \\
\hline $\begin{array}{l}\text { Aumento del índice de } \\
\text { dependencia demográfica. }\end{array}$ & $\begin{array}{l}\text { La relación de la población de } 0 \text { a } 14 \text { años, sumada a la } \\
\text { de más de } 65 \text { respecto a aquella entre } 15 \text { y } 64 \text {, tuvo un } \\
\text { decrecimiento intercensal del } 21 \% \text {. }\end{array}$ \\
\hline $\begin{array}{l}\text { Reducción del índice de } \\
\text { masculinidad. }\end{array}$ & $\begin{array}{l}\text { La relación de los hombres respecto a las mujeres } \\
\text { tuvo un crecimiento intercensal del } 1 \% \text {. Los hombres } \\
\text { han representado el } 47 \% \text { del total de la población del } \\
\text { AMVA, entre } 2005 \text { y } 2018 \text {. No obstante, mientras en } \\
\text { el } 2005 \text { había } 89 \text { hombres por cada } 100 \text { mujeres en el } \\
2018 \text { pasaron a } 90 \text {. }\end{array}$ \\
\hline $\begin{array}{l}\text { Reducción de la brecha de } \\
\text { pobreza. }\end{array}$ & $\begin{array}{l}\text { Según el Banco Mundial (2016), la brecha pasó de } \\
15,1 \text { a } 10,3 \text { entre } 2010 \text { y } 2015 .\end{array}$ \\
\hline $\begin{array}{l}\text { Desaceleración } \\
\text { de las economías } \\
\text { latinoamericanas. }\end{array}$ & $\begin{array}{l}\text { Según el Banco Mundial (2016), el mundo pasó de } \\
\text { un crecimiento del } 4,36 \% \text { en } 1961 \text { al } 3 \% \text { en } 2018 \text {, } \\
\text { expresando una tendencia bajista. Por su parte, } \\
\text { América Latina y el Caribe pasaron del } 6,5 \% \text { al } 1,5 \% \text {. } \\
\text { Colombia pasó del } 5 \% \text { al } 2,7 \% \text {. En otros términos, } \\
\text { hubo una reducción relativa del } 77 \% \text { y del } 46 \% \\
\text { respectivamente en } 57 \text { años, lo cual implicó dejar de } \\
\text { crecer por encima del promedio mundial. }\end{array}$ \\
\hline Conectividad. & $\begin{array}{l}\text { Según el Banco Mundial (2016), América Latina y } \\
\text { el Caribe pasaron del } 0,014 \% \text { de la población total } \\
\text { conectada a internet a } 63,2 \% \text {, muy por encima del } \\
\text { promedio mundial. Colombia pasó del } 0,107 \% \text { en } \\
1994 \text { a } 62,26 \% \text { en } 2017 \text {, por debajo del promedio } \\
\text { latinoamericano. }\end{array}$ \\
\hline
\end{tabular}




\begin{tabular}{|c|c|}
\hline Tendencias & Descripción \\
\hline Computación en la nube. & $\begin{array}{l}\text { Según Statista (2019), el mercado mundial de la } \\
\text { computación en la nube, entre el } 2013 \text { y el } 2018 \text {, } \\
\text { pasó de } 12 \text { mil a } 43 \text { millones de USD, lo cual muestra } \\
\text { una tendencia alcista acelerada con un crecimiento } \\
\text { acumulado del } 258 \% \text { en cinco años. }\end{array}$ \\
\hline Comercio electrónico. & $\begin{array}{l}\text { Statista (2019) afirma que en un minuto se gastan } \\
\text { cerca del millón de dólares online, lo que representa } \\
\text { una demanda muy atractiva que exige a las empresas } \\
\text { y emprendedores incursionar en el marketing digital. }\end{array}$ \\
\hline Automatización. & $\begin{array}{l}\text { Según el Foro Económico Mundial (2018), "[...] la } \\
\text { automatización eliminará } 75 \text { millones de empleos para } \\
2025 \text {, pero creará } 133 \text { millones de nuevas funciones" } \\
\text { (p. 10). Al respecto plantea que "[...] en el año } 2018 \\
\text { el } 71 \% \text { de las horas totales de trabajo las ejerce un } \\
\text { humano y el } 29 \% \text { una maquina con inteligencia } \\
\text { artificial. Para el } 2025 \text { la relación sería de } 48 \% \text { y } \\
52 \% \text { respectivamente, lo que quiere decir que habrá } \\
\text { prevalencia laboral de las máquinas" (p.10). }\end{array}$ \\
\hline
\end{tabular}

Según Statista (2019), los dispositivos conectados Internet de las cosas a internet pasaron de 15,41 a 75,44 billones, lo cual muestra una tendencia alcista acelerada con un crecimiento acumulado del $389 \%$ en diez años.

Según Statista (2019), los ingresos de la industria Big Data. del Big Data crecerán exponencialmente pasando de 35 a 103 mil millones de USD, lo que equivale a un crecimiento acumulado del $194 \%$ en 10 años.

América Retail (2018), citando a Constellation Research, afirma que "[...] para 2025 el mercado de la inteligencia artificial superará los 100 mil millones Inteligencia artificial. de dólares". Esto es coherente con lo estimado por Accenture (2017), quien estima que "la inteligencia artificial tiene el potencial de añadir un punto entero de porcentaje a las tasas anuales de crecimiento económico de Sudamérica hacia 2035" (p.3).

Según Statista (2019), la mayor cantidad de empresas de blockchain en el mundo está en Estados Unidos, Gran Bretaña, Canadá, Singapur e India. Colombia no aparece en el listado. Las criptomonedas y Blockchain. $\quad$ especialmente la minería de bitcoin son un campo de aplicación importante de la tecnología blockchain. Sin embargo, es de aclarar que no es el único y que su uso se expande aceleradamente a temas como la logística de distribución y gestión inteligente de contratos. 


\begin{tabular}{|c|c|}
\hline Tendencias & Descripción \\
\hline Ciberseguridad. & $\begin{array}{l}\text { Gartner (2017) afirma que la creciente ola de } \\
\text { delincuencia cibernética impulsó las ventas en sistemas } \\
\text { de ciberseguridad hasta los } € 85 \text { billones en } 2017 \text {. }\end{array}$ \\
\hline $\begin{array}{c}\text { Apuestas online } \\
\text { especialmente deportivas. }\end{array}$ & $\begin{array}{l}\text { El fenómeno de las apuestas online es relativamente } \\
\text { nuevo en Colombia dado que apenas fue legalizado a } \\
\text { mitad del año 2017. Según Coljuegos, durante el } 2018 \\
\text { se entregaron } \$ 1.247 .156 .414 .388 \text { de los cuales } 33 \text { mil } \\
\text { millones son transferidos al sector salud por el pago } \\
\text { de derechos de explotación. Según Foros Semana y } \\
\text { Fecoljuegos (2017; } 2018) \text {, la creación de plataformas de } \\
\text { apuestas digitales creció en un } 400 \% \text { entre } 2015 \text { y } 2018 \text {. }\end{array}$ \\
\hline Gammers. & $\begin{array}{l}\text { Según Statista (2019), el mercado de los videojuegos } \\
\text { en todo el mundo tuvo un valor de } 115.3 \text { mil millones } \\
\text { de USD en el año } 2018 \text {. }\end{array}$ \\
\hline
\end{tabular}

Elaboración propia, 2019.

También se tuvieron en cuenta las tendencias de comportamiento identificadas para el jugador y el joven no jugador de chance, como una suerte de predicciones sobre la dirección que tomarán estos públicos en un futuro próximo, en torno a este mercado. Esta especie de estado de ánimo general, permite establecer cómo se sentirán los públicos en cuestión y cuáles serían las mejores alternativas para promover un JSA, específicamente el chance.

\section{Tabla 2}

Tendencias en el comportamiento del jugador y del joven no jugador de chance

\begin{tabular}{|c|c|}
\hline Tendencia & Descripción \\
\hline $\begin{array}{c}\text { Transparencia y total } \\
\text { confianza. }\end{array}$ & $\begin{array}{l}\text { Una realidad actual evidente son los bajos niveles } \\
\text { de confianza que poseen las empresas, afectadas } \\
\text { directamente por los constantes cuestionamientos } \\
\text { que los consumidores más exigentes plantean en } \\
\text { todos los sectores económicos. Ganarse la confianza } \\
\text { de los consumidores es un reto clave si se busca la } \\
\text { sostenibilidad empresarial. }\end{array}$ \\
\hline $\begin{array}{l}\text { Ciudadanos globales y } \\
\text { movilidad cultural. }\end{array}$ & $\begin{array}{l}\text { Los jugadores de chance del AMVA son en su } \\
\text { mayoría personas mayores de } 56 \text { años. Si bien el } \\
\text { concepto de ciudadanos globales podría resultarnos } \\
\text { ajeno, el relevo generacional hace que cada vez más } \\
\text { las personas mayores de } 50 \text { años no vean esta época } \\
\text { como el final de sus días, por el contrario, están cada } \\
\text { vez más deseosos de trabajar por más tiempo y buscar } \\
\text { nuevas oportunidades. }\end{array}$ \\
\hline
\end{tabular}




\begin{tabular}{cl}
\hline Tendencia & \multicolumn{1}{c}{ Descripción } \\
\hline $\begin{array}{c}\text { Factor femenino y capital } \\
\text { social. }\end{array}$ & $\begin{array}{l}\text { Equilibrada no es un tema meramente social. Si } \\
\text { bien es importante sacar lo mejor de las personas, y } \\
\text { que las condiciones óptimas para su felicidad estén } \\
\text { dadas, las marcas que sean capaces de entender y } \\
\text { aprovechar el factor femenino, tendrán un camino } \\
\text { seguro a la prosperidad. }\end{array}$ \\
\hline Un mundo mejor y & $\begin{array}{l}\text { El Goodpurpose Study (2012) muestra que "el 87 \% } \\
\text { de los consumidores globales desea que los negocios }\end{array}$ \\
tengan como mínimo el mismo peso en los intereses de \\
la sociedad que en los intereses del negocio" (Como se \\
citó en en Kjaer, s.f., p.450).
\end{tabular}

Elaboración propia, 2019.

A partir de los hallazgos obtenidos a lo largo de esta investigación, se establecen los puntos de mayor relevancia, frente a los cuales las entidades gubernamentales y privadas operadoras de las apuestas permanentes deberán enfocar su gestión para promover un crecimiento organizado y consciente de la realidad del mercado del chance.

La metodología planteada permite identificar los principales retos no solo para describir y evaluar posibles líneas de acción para combatir la ilegalidad y desarrollar el mercado juvenil en el chance, sino que se ordenan y jerarquizan dichas líneas para construir y proyectar la materialización de un escenario apuesta. 
Cada reto se define como un componente estratégico y necesario para la evolución que debe sufrir el chance con miras hacia un futuro rentable y sostenible.

\section{Desafíos para combatir la ilegalidad en el mercado del chance. Reto-Relacionamiento sostenible con nuevos públicos de interés}

¿Quiénes son los nuevos públicos de interés para el mercado del chance? Definitivamente, los jugadores actuales siempre serán una pieza clave dentro de esta estructura, también quienes cumpliendo con el perfil de jugadores potenciales, y que aún no se interesan por este tipo de JSA. Sin embargo, después de este ejercicio de investigación se identificó en los vendedores de chance ilegal una oportunidad importante, teniendo en cuenta su trayectoria, el reconocimiento que tienen por parte de los jugadores, algunos de ellos solo jugadores de chance ilegal, y el conocimiento que tienen del negocio de la venta de chance.

De cara a los vendedores ilegales de chance: ¿qué resulta más atractivo? ¿Cuáles serían esos valores simbólicos y económicos que los convierte en representantes del chance legal? Un sistema de reclutamiento de esta comunidad impactaría positivamente el mercado legal, pero sobre todo los resultados del negocio ilegal.

Lo expuesto sería posible de la mano de una estrategia de competitividad en la que se evidencien claramente las ventajas entre un mercado y otro, pero en el que el atractivo del mercado legal sea comparable e incluso superior, en algún sentido, con el del mercado ilegal.

Los vendedores de chance ilegal serían más receptivos a vender chance legal si, además de ellos, sus jugadores también tienen mayores posibilidades de ganar o los premios a los que puedan tener acceso son más atractivos. Si bien esto representaría un nuevo modelo de juego y de plan de premios, el impacto en el desarrollo territorial y la calidad de vida de todas las personas involucradas en la cadena de valor del chance, además del golpe a la ilegalidad, serían variables suficientemente fuertes como para promover este planteamiento.

Una iniciativa que, junto con el compromiso de entidades públicas y privadas para combatir la ilegalidad, transformaría la realidad del negocio del chance, no solo en el AMVA sino en cualquier otro territorio. 


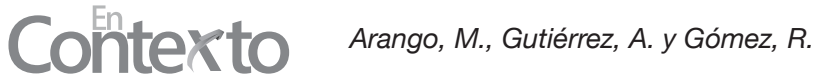

\section{Reto-Red sostenible de distribución}

¿Cómo fortalecer la red de distribución actual que tiene el chance legal? Uno de los grandes hallazgos de esta investigación es la tasa de crecimiento del mercado ilegal del chance respecto a la del mercado legal, tópico que se evidencia en el nivel de penetración existente en cuanto a puntos o agentes de venta de este modelo.

Está claro que promover un crecimiento de puntos de venta sin la correcta y adecuada planificación, podría generar una problemática administrativa y financiera, pero permitir que el mercado ilegal siga creciendo en la proporción que lo hace en la actualidad, podría tener las mismas consecuencias.

Si bien los centros de venta legales deberán seguir en aumento, el desarrollo y fortalecimiento de una fuerza de ventas independiente con mayor proximidad al jugador actual podría ser la respuesta para seguirle el ritmo al mercado ilegal, y frenar su nivel de participación. Más altos niveles de confianza, cercanía y familiaridad, propiciarían un tipo de apuesta en "tiempo real", en la que el jugador podría contar con un canal con mayor disponibilidad y que haga parte de su vida cotidiana.

Esto para quienes quieran mantener dentro de su ritual de apuesta el contacto con otras personas y hallar en esta práctica un espacio de socialización. Pero, por otro lado, está el canal digital de venta de chance, un recurso poco explotado que podría convertirse en una sólida estrategia de crecimiento y que incluso podría cautivar a un público que prefiere mantener sus hábitos de apuesta en privado, esto sin mencionar a los jóvenes jugadores, quienes son asiduos participantes de este tipo de medios para acceder a sus canales de apuesta.

\section{Reto-Sociedad culturizada con la legalidad}

¿Cómo convertir a la comunidad en la mejor aliada de la legalidad? Está claro que la sociedad es permisiva respecto a la ilegalidad y la corrupción; de ahí que prácticas como las apuestas ilegales sean aceptadas e incluso bien vistas, aun cuando en algunos casos esto implique riesgos elevados y poca seguridad sobre el dinero apostado.

El objetivo es trabajar con una comunidad que apenas está forjando un criterio sobre estos aspectos, reconfigurando la percepción social sobre estas prácticas y promoviendo un crecimiento de preceptos en los que lo legal, lo correcto y el bien común sean el gran referente. 
Crear espacios de legalidad en los colegios, las universidades, los trabajos y los barrios, podría transformar este tópico en un tema vigente y, a su vez, en un comportamiento cotidiano, frecuente y vigilado por todos. Todo esto de la mano de una estrategia de comunicación en la que se haga seguimiento y divulgación sobre los impactos en el desarrollo social y territorial que genera la venta de chance legal.

\section{Reto-Transformación tecnológica y digital del mercado del chance}

¿Cómo transformar el chance en un juego digitalmente seguro y tecnológico? El canal digital de venta de chance supone unos retos en cuanto a la seguridad de las transacciones, incluso los mismos sistemas bajo los que actualmente se juega deben estar a la vanguardia en procesos de ciberseguridad y encriptación. Esta debe ser una búsqueda permanente, a pesar de ser un negocio altamente tradicional. El desarrollo de un sistema transaccional encriptado a través de blockchain o el diseño de una estrategia de vigilancia e inteligencia, haciendo uso de tecnologías emergentes como la computación en la nube, el internet de las cosas, el Big Data y la inteligencia artificial serían modelos altamente efectivos para la toma de decisiones en tiempo real y así tener herramientas más eficientes para combatir la ilegalidad y corrupción.

\section{Desafíos para desarrollar el mercado juvenil en el chance. Reto-Relacionamiento sostenible con nuevos públicos de interés}

¿Cómo convertir a los jóvenes en aliados del chance? Una estrategia para este público en particular no puede ser aislada ni diseñada para el corto plazo. Está claro, después de analizar los resultados de las encuestas, que el chance carece de los atributos clave para ser elegido por esta comunidad como un JSA atractivo. Sin embargo, esto no quiere decir que esa transformación que debe surtir el chance, no pueda incluir la mirada del público.

En línea con esto, la creación de grupos de jóvenes, hombres y mujeres, influenciadores que enriquezcan el modelo de juego y lo mantengan actualizado sería una medida de gran eficiencia, tomando de primera mano la información que convertiría al chance en un juego actual y emocionante, que represente para este público tranquilidad, poder, progreso, triunfo y diversión, factores identificados como clave para esta comunidad. Todo esto sin dejar de reconocer las diferencias simbólicas y fisiológico-culturales que los JSA poseen para cada uno de los géneros. 


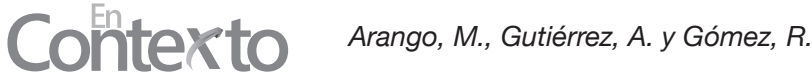

\section{Reto-Chance disruptivo}

¿Cuáles estrategias pueden convertir al chance en un JSA novedoso? Los resultados obtenidos evidenciaron que las apuestas deportivas, la experiencia de apuesta y el sistema de premios son elementos fundamentales en la elección del JSA de preferencia para el público joven.

A partir de esta información, se puede repensar el chance como una apuesta que puede combinarse con otras modalidades de juego, los cuales aporten la emoción de la que este carece o convertir el chance en una experiencia colectiva, en la que se pueda participar con grupos de amigos y tener la posibilidad de ganar montos más llamativos al diluir el margen de riesgo de pérdida en un mayor número de jugadores, o diseñar nuevos planes de premios que activen el sistema de recompensa con motivadores que trasciendan el dinero, pero que sean de gran valor para este público.

\section{Reto-Transformación del mercado del chance tecnológica y digitalmente}

¿Cómo transformar el chance en un juego atractivo, y seguir siendo digitalmente seguro y tecnológico? Si bien ya se contempló este reto dentro de las medidas para combatir la ilegalidad en el mercado del chance, es necesario pensar la transformación tecnológica no solo desde esta perspectiva, sino también como un elemento motivador para que el joven participe de esta modalidad de juego. Ser atractivo para el público joven requiere de unos mecanismos que compartan las mismas características de esta comunidad: velocidad, capacidad de relacionamiento y tecnología son factores comunes de los jóvenes que referencian las búsquedas para engancharse con una determinada actividad.

\section{Reto-Marca posicionada en el inconsciente colectivo intergeneracional}

¿Cómo convertir una marca tradicional en un referente para los jóvenes sin darles la espalda a sus actuales jugadores? La apariencia de la marca puede renovarse de forma tal que equilibre las expectativas del público mayor con la del público joven; las estrategias pueden ejercer una segmentación más evidente y efectiva, hablándole a cada público de los valores que les son afines, en los medios que consumen y a través de los canales que más se ajusten a sus patrones de comportamiento. 
Sin embargo, no se puede ignorar el peso que la tradición puede ejercer en la comunidad joven, esto logrado a través de la promoción de la transmisión intergeneracional de un juego como el chance y su relevancia en el hogar antioqueño, fenómeno que se repite con mayor o menor intensidad en el resto del país.

\section{Conclusiones}

En los últimos años, los JSA han ganado importancia en el país, por su incremento en la participación económica nacional y su expansión a otros modelos de apuestas más novedosos. El crecimiento de esta actividad tiene su explicación en el ingreso de los juegos por internet, la lucha contra la ilegalidad y la constante búsqueda de nuevas alternativas de entretenimiento, acciones que tienen como propósito incentivar la participación de nuevos inversionistas estratégicos y aumentar el aporte al sector salud.

Colombia es un país con tradición apostadora, algunos departamentos más que otros: Antioquia, Cundinamarca y Valle del Cauca, en sumatoria aportan un $60 \%$ de los ingresos a la salud por impuestos recaudados en este juego (Consejo Nacional de Juegos de Suerte y Azar (CNJSA), 2018), pero en general la relación entre la cultura y los JSA ha propiciado una fuerte presencia de negocios dedicados a esta actividad económica a lo largo y ancho del territorio. Así mismo, las nuevas necesidades de un sector cambiante, junto con algunos retos en temas de coordinación entre autoridades y entes territoriales, así como los altos niveles de ilegalidad en las diferentes modalidades de juego y los conflictos sociales que refuerzan la presencia de juegos no autorizados en las regiones, entre otros, han llevado al Estado a definir una serie de estrategias orientadas a hacer más segura y competitiva esta industria.

La principal estrategia gubernamental es una legislación fuerte y en constate evolución, que se adapte a las nuevas formas de apuestas y, por consecuencia, minimice las posibilidades del crecimiento de la ilegalidad en el sector. Pero que, del mismo modo, regule y controle los juegos de mayor tradición que siguen teniendo una participación importante en el mercado de los JSA.

Además, el chance históricamente, tanto a nivel nacional como local, sostiene una tendencia de crecimiento y refleja una estabilidad en el comportamiento de sus ingresos (promedio de crecimiento histórico del 5\%, ${ }^{3}$ que no depende del

3 Información obtenida de reporte Lotería de Medellín, 2019. 


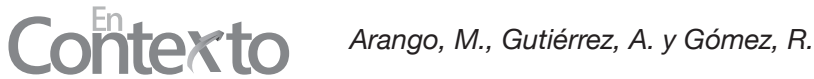

crecimiento de la economía, sino que tiene que ver más con la idiosincrasia, las estructuras culturales y las creencias de los jugadores, sobre todo, de los estratos 1,2 y 3$)$.

Estas cifras, nos permiten establecer que los resultados del presente estudio tienen implicaciones para la búsqueda de estrategias novedosas de mercado y la investigación de los JSA, particularmente de las apuestas permanentes, que, a pesar de su perfil tradicional, evidencian un enorme potencial.

Respecto a la variable de ilegalidad y la necesaria lucha contra ella, por parte del Estado, se pudo establecer que presenta un atractivo especial, porque el jugador puede apostar mínimas cantidades de dinero y ganar con alta frecuencia. Si a estos beneficios se le suman el no pago de impuestos y un margen mayor de ganancia sobre el premio, se puede establecer el porqué del alto nivel de aceptación del que goza el chance ilegal; esto sin mencionar la falta de legitimidad del Estado respecto a las inversiones que se realizan a la salud y que no son visibles para la comunidad.

Se presentan varias razones para que exista un mercado ilegal de los JSA, entre ellas "el monopolio administrado por el Estado con alta carga impositiva, el limitado alcance de las políticas de control por las entidades competentes y los estímulos que se generan por la carga impositiva que tiene el sector formal de JSA" (Zapata et al., 2018, p.34).

Para la exitosa venta del chance ilegal, se reconocen aspectos importantes: se presenta en lugares en donde las autoridades y los vendedores legales de chance no tienen acceso, debido al entorno peligroso, es decir, el chance ilegal se ofrece en lugares en donde las transacciones se hacen en efectivo como en plazas de mercado y barrios de invasión; en estos mismos espacios se presentan, de igual manera, otras prácticas ilegales como el microtráfico y la prostitución (Zapata et al., 2018, p.70), descripción que hace referencia al fenómeno en las principales ciudades del país.

En el AMVA, si bien se repite el anterior escenario, también se evidencia una evolución de la ilegalidad, en la que permea espacios con menos entornos riesgosos o peligrosos, por ejemplo, los parques principales de municipios y barrios, cafeterías, bares e incluso puntos de venta propios que operan de manera clandestina. 
Los anteriores aspectos se convierten en motivadores para que se presente el chance ilegal: por un lado, quien lo vende, ofrece más dinero respecto al mismo número y la misma apuesta, y por el otro, el comprador puede acceder a este juego en su entorno más cercano, en su barrio, y además con personas con las que tiene familiaridad y que le generan confianza.

El mercado ilegal del chance representa un 53\% del mercado legal en el AMVA, según cifras del tamaño físico y monetario determinados en el primer capítulo. Se presentan algunas particularidades especiales: se genera a la vista de todos los participantes y no es considerado de manera abierta como una práctica ilegal, evidenciando una cultura de la ilegalidad, en donde parte de la población cansada ante los hechos de corrupción no legitima que los impuestos sean destinados a la salud, inversión social o a una destinación específica, para lo cual han sido creados. La existencia de una línea muy delgada entre la legitimidad del Estado y la de grupos al margen de la ley, especialmente cuando la población recibe escuelas, colegios, puentes y hospitales por parte de estos grupos y se sienten respaldados por ellos en su vida cotidiana.

Adicionalmente, a los anteriores motivadores descritos, se suman algunos otros aspectos que incrementan la práctica del chance no electrónico, como mayor rentabilidad ( $40 \%$ de diferencia en la ganancia, tanto para el vendedor como para el jugador de chance ilegal, respecto al legal): el no pago de impuestos y el apoyo a su entorno inmediato.

Los avances en la tecnología han permitido mejorar el control de las apuestas; sin embargo, las prácticas ilegales aún continúan. En este aspecto, para la empresa, se le presentan dos retos importantes: uno es participar en la creación de una cultura de la legalidad, desde donde se puntualice a la ciudadanía de los perjuicios tanto a nivel social, económico y de seguridad que ofrece el chance no electrónico; el segundo, en repensar las formas de acceder al chance electrónico desde otras fuentes diferentes a los puntos de venta físicos.

Respecto al componente de desarrollo juvenil, es preciso indicar que, aunque el ejercicio de perfilamiento poblacional ya ha sido desarrollado ampliamente en el país (Coljuegos, 2014; 2015a; 2015b; 2016; 2017) para identificar los comportamientos de juego, nunca se había realizado un énfasis especial en la población joven no jugadora de chance, como punto de partida para comprender las preferencias y motivadores de este segmento e igualmente sus inhibidores frente a esta modalidad de juego. 


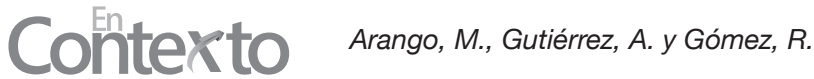

Los hallazgos frente a este abordaje permiten establecer que es de vital importancia ejercer una reingeniería al actual chance electrónico de manera tal que los jugadores potenciales vean en él, una alternativa de juego fresca, emocionante y con posibilidades de ganar.

Según el estudio de McDaniel \& Zuckerman (2003) el interés por el juego presenta un pico importante desde finales de la adolescencia y principios de los veinte y tiene como foco principal la búsqueda de sensaciones impulsivas. Los resultados propios respecto a los jóvenes no jugadores de chance, también permitieron identificar que los JSA en los que las emociones pudieran tener un rol representativo son las modalidades de juego preferidas por esta población. De acuerdo con esto, podemos concluir que el chance está en clara desventaja respecto a otros JSA debido a su enfoque tradicional, a sus modalidades de juego poco llamativas para los jóvenes y a su plan de premios rigurosamente controlado y legislado.

Por otra parte, a partir de los análisis realizados por Peter y Olson (2006), en cuanto al conocimiento que una marca debe tener de su consumidor y las vertientes a través de las que se puede abordar este acercamiento (cognición, comportamiento $\mathrm{y}$ ambiente), se puede determinar que el chance como JSA tradicional y mercado está desaprovechando una enorme cantidad de oportunidades de comunicación e influencia sobre sus públicos cautivos y potenciales.

En cuanto a los apostadores más jóvenes, si bien está claro, como se expresó anteriormente, que el chance no es un juego atractivo para ellos, también se pudo establecer, a partir de este ejercicio investigativo, que es posible generar combinaciones entre el chance y otros JSA que le aporten emoción a la apuesta y que active en el joven estructuras mentales completamente nuevas, que al estar atadas a sus conocimientos, significados y creencias genere como resultado un nuevo consumidor de chance.

Estas reacciones pueden ser incentivadas a través de otras estrategias afines a ellos, como el deporte y el uso de redes sociales, ambos elementos comunes e incluso centrales en la vida de este segmento poblacional. Así como se presentó en el caso neozelandés con el uso de figuras deportivas que legitimen el ejercicio de apostar como una actividad recreativa aceptable (Dyall et al., 2009), o en el caso australiano, en donde una de las formas de comunicación con la población estudiada se da a través de redes sociales, incentivando otras métricas como la confianza del consumidor, la lealtad, la generación de ideas y conocimientos del mercado (Gainsbury et al., 2015). 
La investigación realizada constituye un reto empresarial para la Lotería de Medellín y cualquier otra entidad que intervenga en la operación de JSA, principalmente a nivel nacional, pues es preciso desarrollar no solo una estrategia de mercadeo, sino también una propuesta de impacto social para legitimar el juego legal, crear hábitos saludables de juego y así consolidar al futuro público del chance.

En consecuencia, hay una posibilidad de investigación futura que contribuya a la comprensión de la dinámica de las diferentes formas de juego y su escala de emociones, respecto a los jugadores y no jugadores de chance, teniendo como variables clave el género, la edad y el comportamiento de juego, incluidas las conductas patológicas.

\section{Referencias}

Accenture. (2017). Cómo la inteligencia artificial crecimiento en Sudamérica. Accenture. https://www.accenture.com/_acnmedia/pdf-49/accenturecomo-la-ia-puede-generar-crecimiento-en-sudamerica.pdf

Álvarez, J. (2016). ¿Qué es eso? Breve historia del chance en Colombia. https:// issuu.com/decimotiempo/docs/historia_del_chance_en_colombia

América Retail. (01 de octubre de 2018). Marketing Digital: 6 estadísticas que te harán apostar por la AI. América Retail. https://www.america-retail. com/marketing-digital/marketing-digital-6-estadisticas-que-te-haranapostar-por-la-ai/

Banco Mundial. (02 de octubre de 2016). Para poner fin a la pobreza extrema hacia 2030 es fundamental abordar el problema de la desigualdad. Banco Mundial-BIRF-AIF. https://www.bancomundial.org/es/news/ press-release/2016/10/02/tackling-inequality-vital-to-end-extremepoverty-by-2030

Castaño, N. (2018). Metodologías y estrategias para el desarrollo de la observación en lo público. En Y. Gómez (Ed.), Observatorio público. eGxperiencias, tendencias y desafíos. Lineas de investigación para explorar los campos de las Ciencias Administrativas y de Gestión, Económicas y Contables (pp. 18-46). Publicar-T. https://www.tdea. edu.co/images/tdea/galeria/ebooks_sello_editorial/libro_observatorio_ publico_julio_2019.pdf 


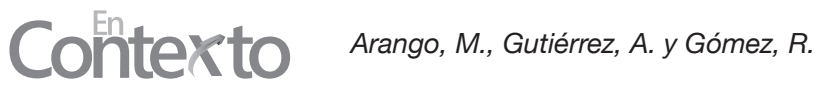

Coljuegos. (2014). Perfil del apostador colombiano 2013. https://www. coljuegos.gov.co/descargar.php?id=200333

Coljuegos. (2015a). Caracterización jugador colombiano de JSA - jugadores. https://www.coljuegos.gov.co/descargar.php?idFile=223317

Coljuegos. (2015b). Presentación Fedelco Coljuegos. http://www.coljuegos. gov.co/descargar.php?idFile $=223883$

Coljuegos. (2016). Acuerdo Nro. 04 de mayo de 2016. Establece el reglamento del juego de suerte y azar en la modalidad novedoso de tipo juegos operados por internet.

Coljuegos. (2017). Mercado y alternativas de juegos de suerte y azar en Colombia. Análisis de mercado. https://www.coljuegos.gov.co/descargar. php?idFile $=231472$

Consejo Nacional de Juegos de Suerte y Azar. (CNJSA). (2018). Estadísticas apuestas permanentes. http://cnjsa.coljuegos.gov.co/documentos. php?id=200524

DANE. (2019). Censo nacional de población y vivienda 2018. https://www. dane.gov.co/index.php/estadisticas-por-tema/demografia-y-poblacion/ censo-nacional-de-poblacion-y-vivenda-2018/informacion-tecnica/ cnpv-presentaciones-en-territorio\#RegionCafetero

Dyall, L., Tse, S., \& Kingi, A. (2009). Cultural icons and marketing of gambling. International Journal of Mental Health and Addiction, 7(1), 84-96.

Foro Económico Mundial. (2018). The future of jobs report. http://www3. weforum.org/docs/WEF_Future_of_Jobs_2018.pdf

Foros Semana y Fecoljuegos. (14 de diciembre de 2017). Foro juegos de suerte y azar: una apuesta al desarrollo. https://www.forossemana.com/cms images/wp-content/uploads/2017/12/ConclusionesColjuegos.pdf 
Foros Semana y Fecoljuegos. (24 de octubre de 2018). Foro juegos de suerte y azar: una industria innovadora. https://www.fecoljuegos.com.co/wpcontent/uploads/2016/04/ConclusionesFecoljuegos.pdf

Gainsbury, S., Hing, N., King, D., \& Delfabbro, P. (2015). Social media marketing and gambling: An interview study of gambling operators in Australia. International Gambling Studies, 1-16.

Gartner. (22 de octubre de 2017). Gartner unveils top predictions for it organizations and users in 2020 and beyond. Gartner. https://www. gartner.com/en/newsroom/press-releases/2019-22-10-gartner-unveilstop-predictions-for-it-organizations-and-users-in-2020-and-beyond

Goodpurpose Study. (2012). Global consumer survey. http://www.fairtrade. travel/source/websites/fairtrade/documents/Edelman_Goodpurpose_Global_Consumer_Survey.pdf

Kjaer, A. (s.f.). Imaginar el futuro. A la vanguardia de un mundo cambiante. Tendencias de consumo para el futuro. https://www.bbvaopenmind.com/ wp-content/uploads/2013/03/BBVA-OpenMind-Imaginar-el-futuro-Ala-vanguardia-de-un-mundo-cambiante-Tendencias-de-consumo-parael-futuro-Anne-Lise-Kjaer.pdf.pdf

McDaniel, S., \& Zuckerman, M. (2003). The relationship of impulsive sensation seeking and gender to interest and participation in gambling activities. Social Behavior and Personality An International Journal, 1385-1400.

Peter, J., y Olson, J. (2006). Comportamiento del consumidor y estrategia de marketing. McGraw-Hill.

Portafolio. (4 de abril de 2019a). El chance, juego de suerte y azar con el mercado ilegal más grande. Portafolio. https://www.portafolio.co/economia/ juegos-de-azar-y-tragamonedas-ilegales-mueven-1-8-billones-528230

Portafolio. (11 de septiembre de 2019b). El chance, el "hijo pobre" de los juegos de azar, sigue siendo el ganador. Portafolio. https://www.portafolio.co/ negocios/asi-se-mueve-el-mercado-de-chance-en-el-pais-533474 


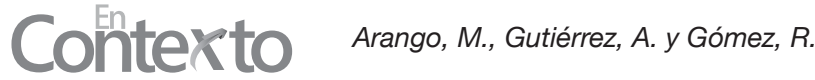

Statista. (27 de marzo de 2019). The sky is the limit for cloud gaming. Statista. https://www.statista.com/chart/17501/cloud-gaming/

Tecnológico de Antioquia I.U. (2018). Contrato interadministrativo No. 78.

Zapata, J., Rico, D., Wiesner, D., Goyeneche, L., Trespalacios, D., y Urrutia, D. (2018). Caracterización y estimación del mercado ilegal de juegos de suerte y azar en Colombia. Fedesarrollo. https://www. repository.fedesarrollo.org.co/bitstream/handle/11445/3754/Repor_ Septiembre_2018_Zapata_et_al.pdf? sequence $=3 \&$ isAllowed $=\mathrm{y}$

\section{Para citar este artículo:}

Arango, M., Gutiérrez, A. y Gómez, R. (2020). Relación entre la responsabilidad social corporativa y las multinacionales. EnContexto, 8(13), 137-168. 